\title{
PERBANDINGAN AKURASI PEMERIKSAAN METODE DIRECT SLIDE DENGAN METODE KATO-KATZ PADA INFEKSI KECACINGAN
}

\author{
Rizka Sofia $^{1}$ \\ ${ }^{1}$ Bagian Parasitologi Fakultas Kedokteran Universitas Malikussaleh \\ Corresponding author : drrizkasofia@gmail.com
}

\begin{abstract}
Abstrak
Infeksi cacing yang sering terjadi pada anak-anak adalah cacing jenis soil-transmitted. Soil transmitted helminth (STH) merupakan cacing golongan Nematoda, khususnya yang berhabitat di intestinal. Pemeriksaan infeksi kecacingan dapat dilakukan secara kualitatif dan kuantitatif. Pemeriksaan kualitatif yang sering digunakan adalah metode direct slide, sedangkan pemeriksaan kuantitatif yang sering digunakan adalah metode Kato Katz. Metode direct slide cepat dan baik untuk infeksi berat, tetapi untuk infeksi yang ringan sulit ditemukan telur-telurnya. Sedangkan, metode Kato Katz menunjukkan sensitifitas yang lebih baik untuk mendeteksi infeksi A.lumbricoides dan T.trichiura serta pada cacing tambang menunjukkan sensitifitas yang lebih rendah. Metode Kato katz memiliki kapasitas yang rendah untuk mendiagnosis cacing tambang, tetapi memiliki sensitifitas yang tinggi mendeteksi Schistosoma mansoni, A.lumbricoides dan T.trichiura. Penelitian ini bertujuan untuk membandingkan akurasi pemeriksaan infeksi kecacingan antara metode direct slide dengan metode Kato-Katz dengan melakukan pemeriksaan sampel feses. Penelitian ini akan dilakukan pada murid Sekolah Dasar Negeri 4 Lapang, Aceh Utara. Sampel yang digunakan dalam penelitian ini berjumlah 58 sampel dengan menggunakan random sampling. Analisa data dilakukan dengan menghitung nilai sensitivitas dan spesivisitas metode direct slide dibandingkan dengan metode Kato-Katz dengan menggunakan tabel 2x2. Hasil penelitian menunjukkan bahwa jumlah sampel yang terinfeksi STH lebih banyak ditemukan dengan metode Kato-Katz. Hasil pengukuran dengan metode direct slide dan metode KatoKatz menunjukkan prevalensi tertinggi infeksi STH adalah infeksi A. lumbricoides. Metode direct slide menghasilkan tingkat sensitifitas sebesar $89,09 \%$ dan spesifisitas sebesar $100 \%$. Metode direct slide menghasilkan PPV sebesar 100\% dan NPV sebesar 33,33\%.
\end{abstract}

Kata Kunci: infeksi kecacingan, direct slide, kato katz 


\section{COMPARISSION ACCURACY EXAMINATION IN WORM INFECTION BETWEEN DIRECT SLIDE METHOD AND KATO-KATZ}

Worm infection that often occurs in children is a type of soil-transmitted worms. Soil transmitted helminth (STH) is a class of Nematode worms, especially those in the intestinal habitat. Examination of worm infection can be done qualitatively and quantitatively. Qualitative examination of the commonly used method is direct slide, while the quantitative examination of the commonly used method is Kato Katz. Direct slide method is fast and good for severe infections, but for mild infections are hard to find eggs. While, Kato Katz method showed better sensitivity for detecting infection and T. trichiura A. lumbricoides and the hookworm showed lower sensitivity. Kato Katz method has a low capacity to diagnose hookworm, but has a high sensitivity detection of Schistosoma mansoni, A. lumbricoides and T. trichiura. This study aimed to compare the accuracy examination worm infection between direct slides method with Kato-Katz method by examining a stool sample. This research was conducted at SD Negeri 4 Lapang, North Aceh. The sample used in this study was 58 samples by using random sampling. Data analysis was done by calculating the sensitivity and specificity of direct slide and Kato-Katz method and compared it by using a $2 \times 2$ table. The results showed that the number of samples infected with STH more founded by Kato-Katz method. The results of measurements with direct slide and Kato-Katz method showed the highest prevalence of STH infections are infections A. lumbricoides. Direct slide method generates the sensitivity of $89.09 \%$ and a specificity of $100 \%$. Direct slide method generates PPV of $100 \%$ and NPV of $33,33 \%$.

Keywords: worm infection, direct slide, kato katz

\section{PENDAHULUAN}

Infeksi kecacingan yang ditularkan melalui tanah (Ascaris lumbricoides, Trichuris trichiura, dan Hookworm) tersebar luas di daerah tropis dan sub-tropis. ${ }^{1}$ Infeksi kecacingan yang ditularkan melalui tanah di Indonesia merupakan masalah kesehatan utama di daerah urban dan semi urban yang memiliki sanitasi lingkungan buruk, kebiasaan higiene kurang baik dan status sosial ekonomi yang rendah. ${ }^{2}$ Parasit cacing yang paling banyak menginfeksi adalah Ascaris lumbricoides, cacing tambang (hookworm) dan Trichuris trichiura. $^{3}$

Usia anak-anak merupakan kelompok berisiko terinfeksi kecacingan ini karena aktifitas bermain anak-anak lebih banyak di tanah dan sungai. ${ }^{4}$ Kelompok umur terbanyak yang terinfeksi adalah pada usia 6-12 tahun atau pada tahapan sekolah dasar. ${ }^{5}$

Pemeriksaan infeksi kecacingan dapat dilakukan secara pemeriksaan kualitatif dan kuantitatif. Pemeriksaan kualitatif yang lebih sering digunakan adalah teknik apusan langsung (direct slide), karena ini lebih sederhana dan mudah untuk dilakukan serta tidak perlu menentukan derajat infeksi kecacingan. Sedangkan, pemeriksaan kuantitatif yang paling sering digunakan adalah metode Kato Katz. Metode ini dilakukan untuk menentukan 
derajat infeksi kecacingan.

Metode langsung (direct slide) mempunyai kelemahan yaitu jika bahan untuk membuat sediaan secara langsung terlalu banyak, maka preparat menjadi tebal sehingga telur menjadi tertutup oleh unsur lain. Metode direct slide cepat dan baik untuk infeksi berat, tetapi untuk infeksi yang ringan sulit ditemukan telur-telurnya. ${ }^{6}$ Sedangkan, metode Kato katz menunjukkan sensitifitas yang lebih baik untuk mendeteksi infeksi A.lumbricoides dan T.trichiura dan pada cacing tambang menunjukkan sensitifitas yang lebih rendah. Metode Kato Katz memiliki kapasitas yang rendah untuk mendiagnosis cacing tambang, tetapi memiliki sensitifitas yang tinggi mendeteksi Schistosoma mansoni, A.lumbricoides dan T.trichiura. $^{7}$

Sensitivitas dan spesifitas merupakan dua indikator yang menunjukkan validitas suatu pemeriksaan diagnostik. ${ }^{8}$ Semakin tinggi nilai sensitivitas dan spesifisitasnya, maka semakin akurat suatu pemeriksaan dalam melakukan penegakan diagnosis.

\section{METODE PENELITIAN}

Penelitian ini adalah penelitian analitik dengan menggunakan rancangan uji diagnostik untuk membandingkan akurasi pemeriksaan infeksi kecacingan antara metode direct slide dengan metode Kato-Katz dengan melakukan pemeriksaan sampel feses. Penelitian ini akan dilakukan pada murid Sekolah Dasar Negeri 4 Lapang, Aceh Utara. Pemeriksaan feses dilakukan di Laboratorium Parasitologi Fakultas Kedokteran Universitas Malikussaleh.

Populasi dalam penelitian ini adalah seluruh murid Sekolah Dasar Negeri 4 Lapang yang berjumlah 87 murid. Sampel yang digunakan dalam penelitian ini berjumlah 58 sampel dengan menggunakan random sampling yang memenuhi kriteria ekslusi yaitu tidak minum obat kecacingan selama 6 bulan terakhir.

\section{Cara menghitung telur cacing}

Adapun cara menghitung jumlah telur cacing dalam feses adalah sebagai berikut:

NEPG (number of egg per gram) $=\mathrm{R} \times \mathrm{Y}$

$R=\frac{1.000}{41,7}=24$

$\mathrm{Y}=$ jumlah telur per slide

Keterangan :

41,7 = Berat tinja dalam template

$\mathrm{R}$ = Hasil pembagian $1 \mathrm{~g}(1000 \mathrm{mg})$ tinja dibagi dengan berat tinja sesuai ukuran lubang karton (mg) 
Tabel 1. Klasifikasi Intensitas Infeksi Berdasarkan Jumlah Telur Per Gram (WHO,

\begin{tabular}{cccc} 
2012) & \multicolumn{4}{c}{} \\
\cline { 2 - 4 } Jenis Cacing & \multicolumn{3}{c}{ Intensitas infeksi ( Jumlah telur/gram ) } \\
\cline { 2 - 4 } & Ringan & Sedang & Berat \\
\hline A. lumbricoides & $1-4999$ & $5000-49999$ & $\geq 50000$ \\
T. trichura & $1-999$ & $1000-9999$ & $\geq 10000$ \\
Cacing Tambang & $1-1999$ & $2000-3999$ & $\geq 4000$ \\
\hline
\end{tabular}

\section{Cara Menghitung Prevalensi}

(a) PAL $=\frac{\text { Jumlah specimen positif telur } \text { A.lumbricoides }}{\text { Jumlah specimen yang diperiksa }} \times 100 \%$

(b) PAL $=\frac{\text { Jumlah specimen positif telur } T \text {.trichiura }}{\text { Jumlah specimen yang diperiksa }} \times 100 \%$

(c) $\mathrm{PAL}=\frac{\text { Jumlah specimen positif telur cacing tambang }}{\text { Jumlah specimen yang diperiksa }} \times 100 \%$

Keterangan : PAL (Prevalensi A. lumbricoides)

PTT (Prevalensi T. trichiura)

PCT (Prevalensi Cacing Tambang)

\section{Cara Menghitung Sensitivitas dan Spesifisitas:}

$$
\begin{aligned}
& \text { Sensitifita }(\%)=\frac{\text { Positif Benar }}{\text { Positif Benar }+ \text { Negatif Palsu }} \times 100 \% \\
& \text { Spesifisita }(\%)=\frac{\text { Negatif Benar }}{\text { Positif Palsu }+ \text { Negatif Benar }} \times 100 \%
\end{aligned}
$$

Analisa data dilakukan dengan menghitung nilai sensitifitas dan spesifisitas metode direct slide dibandingkan dengan metode Kato-Katz dengan menggunakan tabel 2x2.

Tabel 2. Tabel Perhitungan Nilai Sensitifitas dan Spesifisitas

\begin{tabular}{ccc}
\hline Pemeriksaan feses dengan & \multicolumn{2}{c}{ Pemeriksaan feses dengan metode Kato-Katz } \\
\cline { 2 - 3 } metode direct slide & Positif infeksi STH & Negatif infeksi STH \\
\hline Positif infeksi STH & Positif Benar & Positif Palsu \\
Negatif infeksi STH & Negatif Palsu & Negatif Benar \\
\hline
\end{tabular}

\section{HASIL PENELITIAN}

Distribusi frekuensi hasil pemeriksaan feses 
Hasil penelitian menunjukkan bahwa dari 58 sampel penelitian yang diperiksa dengan metode direct slide terdapat 49 sampel $(84,48 \%)$ terinfeksi STH dan dengan metode gold standard (Kato-Katz) terdapat 55 sampel (94,82\%) terinfeksi STH. Berdasarkan jenis kelamin, responden yang paling banyak terinfeksi STH yaitu responden perempuan $(93,33 \%)$.

Tabel 3. Distribusi Frekuensi Hasil Pemeriksaan Feses Berdasarkan Metode Pemeriksaan

\begin{tabular}{cccc}
\hline Metode Pemeriksaan & Hasil Test & N & \% \\
\hline \multirow{2}{*}{ Direct Slide } & Positif & 49 & 84,48 \\
& Negatif & 9 & 15,51 \\
\multirow{2}{*}{ Kato-Katz } & Positif & 55 & 94,82 \\
& Negatif & 3 & 5,17 \\
\hline
\end{tabular}

Tabel 4. Distribusi Frekuensi Hasil Pemeriksaan Feses Berdasarkan Jenis Kelamin

\begin{tabular}{cccc}
\hline Jenis Kelamin & Hasil Test & $\mathrm{N}$ & $\%$ \\
\hline \multirow{2}{*}{ Laki-Laki } & Positif & 27 & 96,42 \\
& Negatif & 1 & 3,57 \\
\multirow{2}{*}{ Perempuan } & Positif & 28 & 93,33 \\
& Negatif & 2 & 6,66 \\
\hline
\end{tabular}

Distribusi frekuensi hasil tes dengan metode direct slide berdasarkan jenis STH dan pengukuran

Hasil pengukuran dengan metode direct slide menunjukkan sebanyak 41 orang terinfeksi A. lumbricoides atau prevalensi A. lumbricoides 70\%, 33 orang terinfeksi $T$. trichiura atau prevalensi T. trichiura 25\%, dan 21 orang terinfeksi hookworm atau prevalensi hookworm 36\%. Prevalensi tertinggi adalah prevalensi infeksi A. lumbricoides (70\%).

Tabel 5. Distribusi Frekuensi Hasil Tes dengan Metode Direct Slide Berdasarkan Jenis STH dan Pengukuran

\begin{tabular}{lccc}
\hline \multirow{2}{*}{ Jenis STH } & Hasil Test & Metode Direct Slide \\
\cline { 3 - 4 } A. Lumbricoides & Positif & 41 & $\%$ \\
\hline \multirow{3}{*}{ T. trichiura } & Negatif & 17 & 70 \\
\multirow{2}{*}{ Hook worm } & Positif & 33 & 30 \\
& Negatif & 25 & 25 \\
& Positif & 21 & 36 \\
& Negatif & 37 & 64 \\
\hline
\end{tabular}

*Nilai persentase adalah angka prevalensi untuk masing-masing jenis cacing STH

Distribusi frekuensi hasil tes dengan metode kato-katz berdasarkan jenis sth dan pengukuran 
Hasil pengukuran dengan metode Kato-Katz menunjukkan sebanyak 49 orang terinfeksi A. lumbricoides atau prevalensi A. lumbricoides 84\%, 39 orang terinfeksi $T$. trichiura atau prevalensi T. trichiura $67 \%$, dan 30 orang terinfeksi hookworm atau prevalensi hookworm 52\%. Prevalensi tertinggi infeksi A. lumbricoides (84\%).

Tabel 6. Distribusi Frekuensi Hasil Tes dengan Metode Kato-Katz Berdasarkan Jenis STH dan Pengukuran

\begin{tabular}{cccc}
\hline \multirow{2}{*}{ Jenis STH } & \multirow{2}{*}{ Hasil Test } & $\mathrm{N}$ & Metode Kato-Katz \\
\cline { 3 - 4 } A. lumbricoides & Positif & 49 & 84 \\
\multirow{2}{*}{ T. trichiura } & Negatif & 9 & 16 \\
\multirow{2}{*}{ Hookworm } & Positif & 39 & 67 \\
& Negatif & 19 & 33 \\
& Positif & 30 & 52 \\
& Negatif & 28 & 48 \\
\hline
\end{tabular}

*Nilai persentase adalah angka prevalensi untuk masing-masing jenis cacing STH

Perbandingan hasil pemeriksaan metode direct slide dengan metode kato-katz dan uji diagnostik metode direct slide

Pemeriksaan dengan metode direct slide terdapat 49 sampel (84\%) yang positif infeksi STH dan 9 sampel (16\%) yang negatif infeksi STH. Sedangkan dengan metode Kato-Katz terdapat 55 sampel (95\%) yang positif infeksi STH dan 3 sampel (5\%) yang negatif infeksi STH. Hasil pemeriksaan menunjukkan bahwa 49 sampel (84\%) positif infeksi STH dengan metode direct slide dan metode Kato-Katz, tidak ada sampel positif infeksi STH dengan metode direct slide tetapi negatif dengan metode Kato-Katz. Sebanyak 6 sampel (10\%) negatif infeksi STH dengan metode direct slide tetapi positif infeksi STH dengan metode Kato-Katz dan sebanyak 3 sampel (5\%) negatif infeksi STH baik dengan metode Kato-Katz ataupun metode direct slide.

Nilai diagnostik pemeriksaan dengan metode direct slide dalam mendeteksi infeksi STH diperoleh dengan mentabulasi data dan dimasukkan ke dalam tabel $2 \times 2$, kemudian dihitung nilai sensitivitas, spesifisitas, negative predivtive value (NPV) dan positive predictive value (PPV) dengan menggunakan rumus.

Tabel 7. Sensitivitas Metode Direct Slide Mendeteksi Infeksi STH Dibandingkan dengan Baku Emas Metode Kato-Katz

\begin{tabular}{|c|c|c|c|c|}
\hline \multirow{2}{*}{\multicolumn{2}{|c|}{ Metode Direct Slide }} & \multicolumn{3}{|c|}{ Metode Kato-Katz } \\
\hline & & Positif & Negatif & Total \\
\hline \multirow{2}{*}{ Pengukuran } & Positif & 49 & 0 & 49 \\
\hline & Negatif & 6 & 3 & 9 \\
\hline \multicolumn{2}{|c|}{ Total } & 55 & 3 & 58 \\
\hline
\end{tabular}


Berikut ini menunjukkan hasil sensitivitas, spesifisitas, PPV dan NPV pada pemeriksaan metode direct slide dibandingkan dengan baku emas metode Kato-Katz dalam mendeteksi infeksi STH.

$\begin{array}{ll}\text { Sensitifitas } & : 89,09 \% \\ \text { Spesifisitas } & : 100 \% \\ \text { PPV } & : 100 \% \\ \text { NPV } & : 33,33 \%\end{array}$

\section{PEMBAHASAN}

Dari hasil penelitian ini didapatkan bahwa sebagian besar murid SD Negeri 4 Lapang terinfeksi cacing STH yaitu 55 orang murid (94,82\%), Diketahui bahwa prevalensi infeksi kecacingan di Indonesia adalah 60-80\% dan paling banyak menyerang anak usia SD. ${ }^{9}$ Beberapa penelitian tentang infeksi cacing ternyata menunjukkan bahwa anak usia sekolah merupakan golongan yang sering terkena infeksi cacing karena sering berhubungan dengan tanah. ${ }^{5}$ Hal ini dikarenakan rumah para murid SD Negeri 4 Lapang pada umumnya tidak mempunyai jamban dan terbiasa untuk buang air besar di tanah sehingga sangat mudah terinfeksi dengan cacing STH yang perkembangbiakannya memerlukan media tanah. Tidak adanya sumber air sehat dan jamban merupakan salah satu faktor terjadinya infeksi kecacingan. ${ }^{6}$

Hasil penelitian ini menunjukkan bahwa pemeriksaan infeksi STH dengan metode Kato-Katz memberikan hasil positif 55 sampel (94,82\%) yang lebih banyak dibandingkan dengan metode direct slide 49 sampel $(84,48 \%)$. Metode Kato Katz merupakan baku emas untuk pemeriksaan infeksi STH, WHO merekomendasikan metode Kato Katz untuk pemeriksaan infeksi STH. Penelitian yang pernah dilakukan didapatkan sensitivitas dari pemeriksaan Kato Katz mencapai 95\%. ${ }^{10}$

Hasil pengukuran direct slide dan Kato-Katz menunjukkan bahwa prevalensi infeksi STH tertinggi adalah infeksi A.lumbricoides (70\% dan $84 \%)$. Hasil penelitian ini sesuai dengan penelitian yang dilakukan oleh Taye di Ethiopia (2014) yang menunjukkan bahwa prevalensi infeksi A. lumbricoides lebih tinggi (15,2\%) dibandingkan dengan prevalensi Hookworms dan T. trichiura (12.1\%). Hasil penelitian ini juga sesuai dengan dengan penelitian yang dilakukan pada beberapa sekolah dasar di wilayah Indonesia yang menunjukkan prevalensi cacing tertinggi adalah A. lumbricoides (74,70\%-80\%) dan $T$. trichiura $(25,30 \%-68,42 \%) .{ }^{11}$ 
Faktor resiko terjadinya infeksi STH dan tingginya prevalensi disebabkan karena keberadaan berbagai jenis biologik, sosial, tingkah laku dan faktor lingkungan seperti kemiskinan, tempat tinggal di bawah standar dan kebersihan individu dan masyarakat. Beberapa penelitian di negara tropis menunjukan bahwa faktor lingkungan dan tingkah laku mempengaruhi derajat infeksi STH. ${ }^{12}$

Pemeriksaan dengan metode direct slide terdapat 49 sampel (84\%) yang positif infeksi STH dan 9 sampel (16\%) yang negatif infeksi STH. Sedangkan dengan metode Kato-Katz terdapat 55 sampel (95\%) yang positif infeksi STH dan 3 sampel (5\%) yang negatif infeksi STH. Hasil pemeriksaan menunjukkan bahwa 49 sampel (84\%) positif infeksi STH dengan metode direct slide dan metode Kato-Katz, tidak ada sampel positif infeksi STH dengan metode direct slide tetapi negatif dengan metode Kato-Katz. Sebanyak 6 sampel (10\%) negatif infeksi STH dengan metode direct slide tetapi positif infeksi STH dengan metode Kato-Katz dan sebanyak 3 sampel (5\%) negatif infeksi STH baik dengan metode Kato-Katz ataupun metode direct slide. Deteksi infeksi cacing lebih tinggi menggunakan metode KatoKatz, deteksi untuk tiap jenis cacing juga lebih tinggi dengan menggunakan tehnik KatoKatz. ${ }^{11}$

Hasil sensisitifitas metode direct slide adalah $89,09 \%$ dan spesifisitasnya adalah 100\%. Pada dasarnya suatu uji diagnostik merupakan penelitian observasional yang membandingkan hasil dugaan/prediksi suatu pemeriksaan atau test, terhadap suatu nilai baku yang mendekati kebenaran/gold standard. Seberapa besar hasil pemeriksaan dapat mendekati/menduga nilai sebenarnya akan menentukan besarnya akurasi pemeriksaan tersebut, baik dalam kepastian terdapatnya penyakit ataupun kepastian normal atau tidaknya seseorang. ${ }^{9}$

\section{KESIMPULAN}

1. Hasil pengukuran dengan metode direct slide dan metode Kato-Katz menunjukkan prevalensi tertinggi infeksi STH adalah infeksi A. lumbricoides.

2. Pemeriksaan metode direct slide terdapat 49 sampel yang positif infeksi STH dan 9 sampel yang negatifinfeksi STH, sedangkan metode Kato-Katz terdapat 55 sampel yang positif infeksi STH dan 3 sampel yang negatif infeksi STH.

3. Sampel yang positif infeksi STH dengan metode direct slide dan metode Kato-Katz sebanyak 49 sampel.

4. Tidak ditemukannya sampel positif infeksi STH dengan metode direct slide tetapi negatif dengan metode Kato-Katz. 
5. Sebanyak 6 sampel menunjukkan hasil yang negatif dengan metode direct slide tetapi positif dengan metode Kato-Katz dan 3 sampel yang negatif dengan metode Kato-Katz dan metode direct slide.

6. Metode direct slide menghasilkan tingkat sensitifitas sebesar $89,09 \%$ dan spesifisitas sebesar $100 \%$.

7. Metode direct slide menghasilkan PPV sebesar 100\% dan NPV sebesar 33,33\%.

Saran pada penelitian ini adalah:

1. Pihak Sekolah bekerja sama dengan pihak Puskesmas untuk mengadakan penyuluhan infeksi kecacingan.

2. Pihak Puskesmas mengadakan screening infeksi kecacingan STH pada siswa SD di wilayah kerja Puskesmas.

\section{Ucapan Terima Kasih}

Peneliti berterima kasih kepada Fakultas Kedokteran Universitas Malikussaleh yang telah memberi kesempatan untuk melakukan penelitian ini, dan juga kepada para responden yang telah bersedia ikut serta dalam penelitian ini.

\section{DAFTAR PUSTAKA}

1. Chatterjee KD. 2009. Parasitology: Protozoology and Helminthology. Thirteen Edition, Calcutta, New Delhi: Thomson Press.

2. Natadisastra D, Ridad A. 2009. Parasitologi Kedokteran: ditinjau dari organ tubuh yang diserang. Editor Djaenuddin Natadisastram D, Agoes R. Jakarta: Penerbit EGC.

3. Sandy S, Sumarni S, Soeyoko. 2015. Analisis Model Faktor Risiko yang Mempengaruhi Infeksi Kecacingan yang Ditularkan Melalui Tanah pada Siswa Sekolah Dasar di Distrik Arso Kabupaten Keerom, Papua. Media Litbangkes. Edisi 25. Vol. 1. hal: 1-14.

4. World Health Organization. 2011. Helminths Control in School-age Children: A guaide for managers of control programmes. Second Edition. France: WHO Press.

5. Samad H. 2009. Hubungan Infeksi dengan Pencemaran Tanah oleh Telur Cacing yang Ditularkan Melalui Tanah dan Perilaku Anak Sekolah Dasar Di Kelurahan Tembung Kecamatan Medan Tembung. Tesis. Sekolah Pascasarjana Universitas Sumatra Utara.

6. Altiara, S. 2011. Hubungan Sanitasi Lingkungan Rumah dengan Kejadian Cacingan pada Balita di RW 03 Kelurahan Panggung Kota Tegal. Skripsi. Universitas Negeri Semarang.

7. Speich B, Knoop S, Mohammed K.A. et al. 2010. Comparative cost assessment of the kato-katz and Flotac Techniques for Soil-Transmitted Helmint Diagnosis in Epideiological Surveys. Parasites Vectors. Edisi 3. Vol. 7.

8. Peacock JL, Peacock PJ. 2011. Oxford Handbook Medical Statistics. New York: Oxford University Press Inch.

9. Tumbelaka, Alan R. 2002. Telaah Kritis Makalah Uji Diagnostik. Sari Pediatri. Edisi 4 Vol 2. Hal. $98-102$ 
10. Santos, F.L.N., E.J.L Cerquera, and N.M Soares. 2005. Comparison of the thick smear and Kato-Katz techniques for diagnosis of intestinal helminth infections. Revista da Sociedade Brasileira de Medicina Tropical. Edisi 38. Vol. 2. Hal: 196-198.

11. Tarafder, MR., H Carabin, L Joseph, et al. 2010. Estimating the sensitivity and specificity of Kato-Katz stool examination technique for detection of hookworms, Ascaris lumbricoides and Trichuris trichiura infections in humans in the absence of a 'gold standard'. Int J Parasitol. Edisi 40. Vol. 4. hal: 399-404.

12. Nikolay, B., S.J Brooker, R.L Pullan. 2014. Sensitivity of Diagnostic Tests for Human Soil-Transmitted Helminth Infections: A Meta-Analysis in The Absence of A True Gold Standard. International Journal for Parasitology. Edisi44. Hal: 765-774. 


\section{Lampiran 1. Biodata Penulis}

A. Indetitas Diri

\begin{tabular}{|l|l|l|}
\hline 1 & Nama Lengkap & dr. Rizka Sofia, MKT \\
\hline 2 & Jenis Kelamin & Perempuan \\
\hline 3 & Jabatan Fungsional & Asisten Ahli \\
\hline 4 & NIP & 198001012009122002 \\
\hline 5 & NIDN & 0001018001 \\
\hline 6 & Tempat dan Tanggal lahir & Lhokseumawe, 1 Januari 1980 \\
\hline 7 & E-mail & drrizkasofia@ gmail.com \\
\hline 8 & No. Telp & 081269122494 \\
\hline 9 & Alamat Kantor & Jl. H. Meunasah Uteunkot-Cunda Lhokseumawe \\
\hline 10 & Nomor Telp/fax & - \\
\hline 11 & $\begin{array}{l}\text { Lulusan yang telah } \\
\text { dihasilkan }\end{array}$ & $\begin{array}{l}\text { S-1 }=\text { orang } \\
\text { S-2 = orang } \\
\text { S-3 = - orang }\end{array}$ \\
\hline 12 & Mata Kuliah yang Diampu & Parasitologi \\
\hline
\end{tabular}

\section{B. Riwayat Pendidikan}

\begin{tabular}{|c|c|c|c|}
\hline & S-1 & S-2 & S-3 \\
\hline $\begin{array}{l}\text { Nama Perguruan } \\
\text { Tinggi }\end{array}$ & Unsyiah & USU & - \\
\hline Bidang Ilmu & Kedokteran & Kedokteran & - \\
\hline Tahun Masuk - Lulus & $1998-2006$ & $2012-2016$ & - \\
\hline Judul Skripsi/Thesis & & $\begin{array}{l}\text { Hubungan Faktor Risiko dengan } \\
\text { Kejadian Malaria Asimtomatik } \\
\text { pada Siswa SMA Negeri1 Krueng } \\
\text { Sabee Aceh Jaya }\end{array}$ & - \\
\hline Nama Pembimbing & & $\begin{array}{l}\text { dr. Tambar Kembaren, Sp.PD- } \\
\text { KPTI, } \\
\text { dra. Merina Panggabean, M.Med, } \\
\text { Sc }\end{array}$ & - \\
\hline
\end{tabular}

\section{Pengalaman Penelitian dalam 5 Tahun Terakhir}

\begin{tabular}{|l|l|l|l|l|}
\hline \multirow{2}{*}{ No } & Tahun & \multicolumn{2}{|c|}{ Judul Penelitian } & \multicolumn{2}{|c|}{ Pendanaan } \\
\cline { 4 - 5 } & 2015 & $\begin{array}{l}\text { Stigma dan Diskriminasi terhadap ODHA } \\
\text { (Studi terhadap Tenaga Kesehatan di } \\
\text { Puskesmas Tanah Pasir Aceh utara) }\end{array}$ & $\begin{array}{c}\text { PNBP } \\
\text { FK } \\
\text { Unimal }\end{array}$ & Rp6.000.000 \\
\hline 2 & 2014 & $\begin{array}{l}\text { Kualitas Pelayanan Kesehatan: } \\
\text { Hubungannya dengan Kepatuhan Berobat } \\
\text { Pasien Hipertensi (Survey pada Puskesmas }\end{array}$ & Mandiri & - \\
\hline
\end{tabular}


D. Pengalaman Pengabdian Kepada Masyarakat dalam 5 Tahun Terakhir

\begin{tabular}{|l|l|l|l|l|}
\hline \multirow{2}{*}{ No } & \multirow{2}{*}{ Tahun } & \multirow{2}{*}{ Judul Pengabdian Kepada Masyarakat } & \multicolumn{2}{|c|}{ Pendanaan } \\
\cline { 4 - 5 } & & Sumber & Jumlah (Juta) \\
\hline & & & & \\
\hline
\end{tabular}

E. Publikasi Artikel Ilmiah dalam Jurnal dalam 5 Tahun Terakhir

\begin{tabular}{|l|l|c|l|}
\hline No. & \multicolumn{1}{|c|}{ Judul Artikel Ilmiah } & Nama Jurnal & $\begin{array}{l}\text { Vulume/Nomor/ } \\
\text { Tahun }\end{array}$ \\
\hline 1 & $\begin{array}{l}\text { Kualitas Pelayanan Kesehatan: } \\
\text { Hubungannya dengan Kepatuhan Berobat } \\
\text { Pasien Hipertensi (Survey pada } \\
\text { Puskesmas Batoh, Banda Aceh) }\end{array}$ & Ekonis & $\begin{array}{l}\text { Vol 13, No 1, } \\
\text { Februari 2015 }\end{array}$ \\
\hline 2 & $\begin{array}{l}\text { Malaria Asimtomatis: Tantangan dalam } \\
\text { Pengendalian Malaria }\end{array}$ & Averrous & $\begin{array}{l}\text { Vol 1, No 2, } \\
\text { November 2015 }\end{array}$ \\
\hline 3 & $\begin{array}{l}\text { Stigma dan Diskriminasi terhadap ODHA } \\
\text { (Studi pada Tenaga Kesehatan di } \\
\text { Puskesmas Tanah Pasir Aceh Utara) }\end{array}$ & Averrous & $\begin{array}{l}\text { Vol 2 No 1, Mei } \\
2016\end{array}$ \\
\hline
\end{tabular}

F. Pemakalah Seminar Ilmiah (Oral Presentation) dalam 5 Tahun Terakhir

\begin{tabular}{|l|l|c|c|}
\hline No & Nama Pertemuan Ilmiah/Seminar & Judul Artikel Ilmiah & $\begin{array}{c}\text { Waktu dan } \\
\text { Tempat }\end{array}$ \\
\hline & - & & \\
\hline
\end{tabular}

G. Karya Buku dalam 5 Tahun Terakhir

\begin{tabular}{|c|c|c|c|c|}
\hline No & Judul Buku & Tahun & Jumlah Halaman & Penerbit \\
\hline & & & & \\
\hline
\end{tabular}

H. Perolehan HKI dalam 5-10 Tahun Terakhir

\begin{tabular}{|l|l|l|l|l|}
\hline No & Tahun & Judul/Tema HKI & Jenis & Nomor P/ID \\
\hline 1. & - & - & - & - \\
\hline
\end{tabular}

Demikian biodata ini saya buat dengan sebenarnya.

Lhokseumawe, 31 Januari 2017

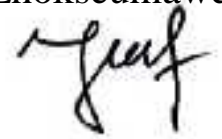

dr. Rizka Sofia, MKT

NIP 198001012009122002 


\section{HALAMAN PERNYATAAN ORISINALITAS}

Karya tulis ini adalah hasil karya penulis sendiri,

dan semua sumber baik yang dikutip maupun dirujuk telah penulis nyatakan dengan benar.

Tanda Tangan : Mizka Sofia 
